\title{
Special Significance of Non-Drosophila Insects in Aging
}

\author{
Siyuan Guo 1,2, Xianhui Wang ${ }^{1,2}$ and Le Kang ${ }^{1,2 *}$ \\ ' State Key Laboratory of Integrated Management of Pest Insects and Rodents, Institute of Zoology, Chinese Academy \\ of Sciences, Beijing, China, ${ }^{2}$ CAS Center for Excellence in Biotic Interactions, University of Chinese Academy of Sciences, \\ Beijing, China
}

OPEN ACCESS

Edited by:

Zhongxia Wu,

Henan University, China

Reviewed by:

Thomas Roeder,

University of Kiel, Germany

Zhangwu Zhao,

China Agricultural University, China

*Correspondence:

Le Kang

Ikang@ioz.ac.cn

Specialty section:

This article was submitted to

Epigenomics and Epigenetics,

a section of the journal

Frontiers in Cell and Developmental

Biology

Received: 26 June 2020 Accepted: 04 September 2020

Published: 22 September 2020

Citation:

Guo S, Wang $X$ and Kang $L$

(2020) Special Significance

of Non-Drosophila Insects in Aging.

Front. Cell Dev. Biol. 8:576571.

doi: 10.3389/fcell.2020.576571
Aging is the leading risk factor of human chronic diseases. Understanding of aging process and mechanisms facilitates drug development and the prevention of agingrelated diseases. Although many aging studies focus on fruit fly as a canonical insect system, minimal attention is paid to the potentially significant roles of other insects in aging research. As the most diverse group of animals, insects provide many aging types and important complementary systems for aging studies. Insect polyphenism represents a striking example of the natural variation in longevity and aging rate. The extreme intraspecific variations in the lifespan of social insects offer an opportunity to study how aging is differentially regulated by social factors. Insect flight, as an extremely high-intensity physical activity, is suitable for the investigation of the complex relationship between metabolic rate, oxidative stress, and aging. Moreover, as a "non-aging" state, insect diapause not only slows aging process during diapause phase but also affects adult longevity during/after diapause. In the past two decades, considerable progress has been made in understanding the molecular basis of aging regulation in insects. Herein, the recent research progress in non-Drosophila insect aging was reviewed, and its potential utilization in aging in the future was discussed.

Keywords: non-Drosophila insects, aging, phenotypic plasticity, flight, diapause

\section{INTRODUCTION}

Aging is regarded as the greatest risk factor of most chronic pathological conditions (Kennedy et al., 2014), and becoming a socioeconomic problem worldwide (He et al., 2016). Between 2000 and 2050 , the percentage of population aged above 60 years is projected to increase from approximately $11 \%$ to $22 \%$ worldwide (United Nations, 2017). As the aging population rapidly grows, agingrelated chronic conditions contribute to the biggest proportion of global healthcare burden, and they are estimated to become the next global public health challenge (World Health Organization, 2017). Thus, understanding of aging mechanisms and identifying aging regulators are becoming increasingly important.

Aging is an extraordinary complex process with a time-dependent loss of structure, function, and physiological integrity (Lopez-Otin et al., 2013). Nine molecular aging hallmarks and seven pillars of aging mechanisms have been characterized, including dysfunction or alterations in metabolism, inflammation, stress adaptation, proteostasis, intercellular communication, mitochondrial functions, telomere state, genomic stability, and epigenetics (Lopez-Otin et al., 2013; Kennedy et al., 2014). Most of the current knowledges about aging mechanisms were contributed by canonical model organisms, including yeast (Saccharomyces cerevisiae), worm 
(Caenorhabditis elegans), fruit fly (Drosophila melanogaster), and house mouse (Mus musculus). Fruit fly is a canonical insect model with advantages of rapid life cycle, high fecundity, convenient and precise genetic manipulation, and easy maintenance (Helfand and Rogina, 2003). Studies on fruit fly aging made remarkable contributions to the understanding of conserved aging-regulatory mechanisms, such as endocrine regulation (Toivonen and Partridge, 2009), oxidative stress (Le Bourg, 2001), epigenetic alterations (Solovev et al., 2018), mitochondrial dysfunctions (Guo, 2012), and genomic instability (Li et al., 2013). Moreover, Drosophila contains approximately $70 \%$ of known disease-related genes in humans (Reiter et al., 2001). Thus, Drosophila has been widely used in modeling aging-related diseases of humans and screening for anti-aging drugs (Piper and Partridge, 2018). However, only focusing on a few number of model species ignores the diversity of longevity and aging traits that have evolved in nature, and the diversity provides an opportunity to study various regulators and mechanisms involved in aging plasticity and senescence evolution (Valenzano et al., 2017). Therefore, more non-canonical systems are required for deep understanding of aging biology.

As the most diverse group of living animals (Mayhew, 2007), insects have the characteristics of phenotypic plasticity, flight, and diapause (Figure 1), which are considerably essential for aging studies. With single genotype, the lifespan of polyphenic insects, especially social insects, can substantially vary depending on the environment (Keller and Jemielity, 2006), thereby providing an opportunity to study the effects of environmental and social factors on aging. Insect flight achieves the highest metabolic rate known (Kammer and Heinrich, 1978), and excessive oxidative stress associated with hyperactive respiratory metabolism may be the potential aging accelerator (Finkel and Holbrook, 2000). In addition, a special stage of developmental arrest called diapause has evolved in many insect species, enabling them to survive extreme conditions, such as winter (Denlinger, 2002). Diapause results in low metabolic activity and a profound extension of insect lifespan, thereby providing an opportunity to understand the mechanism underlying lifespan extension (Denlinger, 2008; Hahn and Denlinger, 2010).

In the past two decades, advances in genomics, genetic manipulation, and gene editing technology enable the aging studies to approach the multiple phenotypes and molecular levels in the non-Drosophila insects. Considerable progress has been achieved in explaining these fantastic aging traits in insects. Here, the recent advances in aging studies of non-Drosophila insects were discussed, and the special values of insects as model systems for aging biology were highlighted.

\section{PHENOTYPIC PLASTICITY AND AGING IN INSECTS}

Studies conducted in twins demonstrated that approximately $25 \%$ of the variation in human longevity is due to genetic factors, while the rest is due to individual behavior and environmental factors (Herskind et al., 1996; Sebastiani and Perls, 2012). The studies on diet, exercise, chemical exposure, and social connection all demonstrate to affect aging and lifespan in humans through complex and largely unknown mechanisms (Lopez-Otin et al., 2016; Yang et al., 2016; Krutmann et al., 2017; Duggal et al., 2018). Understanding the mechanisms underlying the effects of modifiable environments on aging could help develop treatments to promote human health span.

Many insects have evolved the ability of one genotype to produce more than one alternative phenotype when exposed to different environments (Whitman and Ananthakrishnan, 2009; Simpson et al., 2011). Polyphenic insects offer striking examples of natural variation in longevity, such as reproductives and workers in social insects, gregarious and solitary locusts, spring and summer butterflies, and winged and wingless aphids (Keller and Jemielity, 2006; Pener and Simpson, 2009; Ogawa and Miura, 2014; Freitak et al., 2019). Unlike canonical model species, polyphenic insects exhibit up to 100 -fold changes in longevity in response to environmental changes (Remolina and Hughes, 2008), revealing their specific value in studying the effects of environmental factors on aging. Moreover, a number of environmental factors are involved in regulating the phenotypic plasticity of insects (Whitman and Ananthakrishnan, 2009; Simpson et al., 2011). Diet, reproduction, behavior, social interaction, population density, photoperiodic cues, and temperature contribute to lifespan variations in polyphenic insects (Keller and Jemielity, 2006; Pener and Simpson, 2009; Ogawa and Miura, 2014; Freitak et al., 2019). Therefore, the extreme lifespan differences and enormous influencing factors provide an opportunity to deeply understand the mechanisms behind aging plasticity induced by complex environmental changes.

The differences in the lifespan of divergent morphs of butterflies, aphids, and locusts are suitable samples for studying the effects of photoperiodic cues and temperature, environmental stress, and population density on aging, respectively (Pener and Simpson, 2009; Ogawa and Miura, 2014; Freitak et al., 2019). Although previous studies have discovered some interesting aging characteristics, such as key roles of population density at the early life on locust aging (Boerjan et al., 2011) and the positive relationship between immune activity and longevity in seasonally polyphenic butterfly (Freitak et al., 2019), the mechanisms remain unknown.

\section{SOCIAL INSECTS IN AGING}

Social insects such as honey bees, bumble bees, ants, and termites, represent the ideal model systems to investigate the mechanisms behind the effects of social factors on aging because of the enormous intraspecific variation in their lifespan and aging rate (Keller and Jemielity, 2006; Kramer et al., 2016). Highly reproductive honeybee queens can survive for two years, whereas sterile workers can only survive between few weeks and one year (Seeley, 1978; Winston, 1987). The reproductives of social ants and termites can live up to 30 years (Hölldobler and Wilson, 1990), while workers frequently have 10-fold shorter lifespans (Kramer and Schaible, 2013). Moreover, the aging rate and lifespan of workers considerably vary depending 


\section{Insect aging}

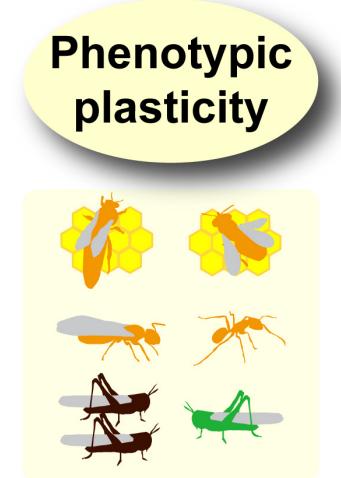

Environment Social factors $\Rightarrow$ Aging

\section{Insect traits}

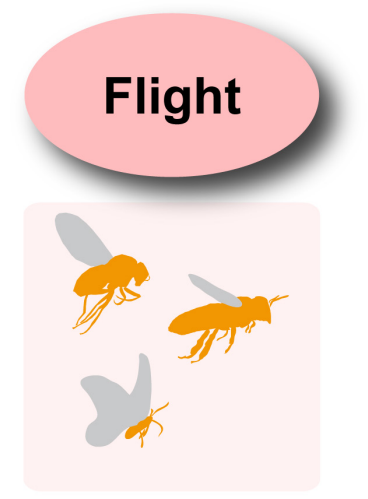

Extreme high metabolic rate

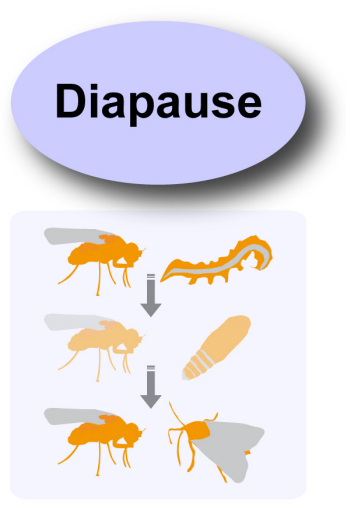

Aging intervention

\section{Regulatory mechanisms}

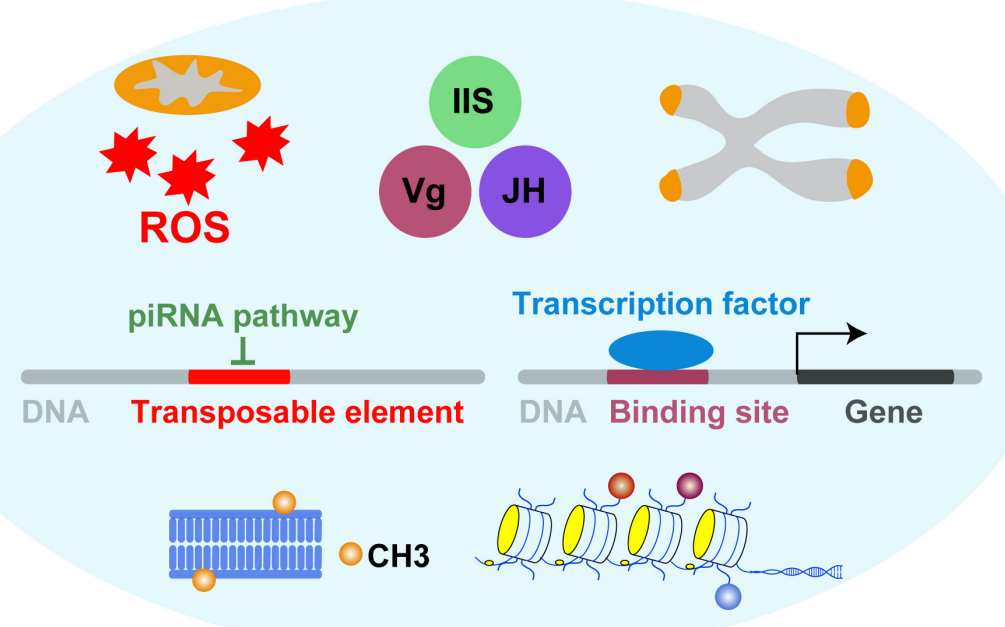

FIGURE 1 | Overview of insect traits with aging-regulatory functions and major molecular mechanisms underlying the effects of these insect traits. Phenotypic plasticity, flight, and diapause have effects on aging. The representative insects and the research implications are shown. Several factors, such as oxidative stress, endocrine factors, telomere, transposable elements, transcription factors, and epigenetics, play important roles in the effects of these insect traits.

on environmental and task changes. For example, the tasks of honeybee workers change in an orderly and usually agedependent manner, with young workers performing nursing duties and old ones foraging (Winston, 1987). The timing of transition from in-hive tasks to foraging is the most significant predictor of worker lifespan, because foragers senesce faster than their same-aged nurse counterparts (Seehuus et al., 2006a; Behrends et al., 2007; Münch et al., 2008; Quigley et al., 2018). Honeybee workers can revert from foraging duties to hive activities, and this reversion is associated with the reversal of aging biomarkers (Amdam et al., 2005; Baker et al., 2012; Herb et al., 2012). Some eusocial ants possess a type of social organization that enables adult workers to become reproductive individuals or gamergates following removal of queen (Brunner et al., 2011). With the reallocation of tasks, the fertile workers could achieve an extended lifespan (Hartmann and Heinze, 2003; Schneider et al., 2011; Kohlmeier et al., 2017).

Several mechanisms are involved in regulating caste-specific aging rate in social insects. First, the difference in antioxidant capacity is one of the putative reasons. The level of vitellogenin $(\mathrm{Vg})$, which protects organisms from oxidative stress (Seehuus et al., 2006b), is higher in honeybee individuals with longer lifespan; for instance, it is higher in queens than in workers and higher in nurses than in foragers (Amdam et al., 2005; Corona et al., 2007; Münch and Amdam, 2010). Polyunsaturated fatty acids that are high in pollen but negligible in royal jelly may result in the cellular membrane of honeybee workers becoming more susceptible to lipid peroxidation than that of queens 
(Haddad et al., 2007; Martin et al., 2019). However, the role of antioxidant genes in queen-biased longevity is controversial. Some studies on honeybees and ants revealed a lower level of antioxidant genes in reproductives than in workers (Parker et al., 2004; Corona et al., 2005; Schneider et al., 2011). Second, endocrine factors also play key roles in caste-specific aging phenotypes. The interaction between insulin/IGF (insulin-like growth factor)-like signaling (IIS), juvenile hormone (JH), and $\mathrm{Vg}$ jointly regulates longevity and reproduction (Rodrigues and Flatt, 2016). However, the aging-regulatory functions of endocrine network are not conserved across social insects. For example, unlike the fire ant and several primitively eusocial insects (Robinson and Vargo, 1997; Bloch et al., 2002), in honeybee workers, JH appears to be life-shortening hormone because $\mathrm{JH}$ and $\mathrm{Vg}$ are configured in a mutually repressive regulatory circuitry during adult stage (Guidugli et al., 2005; Page and Amdam, 2007). Less conserved interaction pathways between endocrine factors (e.g., microRNAs) may contribute to species variation in the longevity regulation of endocrine network (Marco et al., 2010; Nunes et al., 2013). Third, the difference in the maintenance of genomic stability and telomere may be one of potential mechanisms. The heads of termite reproductives, not the major workers, prevent aging-related genomic damages caused by transposable element activity through continued upregulation of the piRNA pathway (Elsner et al., 2018). Telomerase activity displays a 70-fold increase in brains of adult honeybee queens compared to those of adult workers (Korandová and Frydrychová, 2016). The piRNA pathway and telomerase being primarily in germline suggests that the reproductives of highly social insects could be regarded as equivalent to germline of a colony, whereas the workers are equivalent to disposable soma (Elsner et al., 2018). The reproductives have evolved germline-corresponding anti-aging mechanisms to sustain themselves through generations. The fourth potential mechanism is epigenetic regulation. Caste-specific methylation profiles are associated with conserved aging-regulatory pathways, including IIS components, IIS-related metabolic systems, JHresponsive genes, and telomere maintenance (Bonasio et al., 2012; Foret et al., 2012), suggesting that DNA methylation may contribute to the aging differences between queens and workers. Genomic demethylation by pharmacological inhibition increases $\mathrm{Vg}$ expression and extends the lifespan of worker bees (Cardoso-Júnior et al., 2018), indicating the potential roles of DNA methylation in regulating aging in workers.

Although considerable progress has been achieved in understanding the mechanism behind aging divergences in social insects, research evidence remains lacking in some important related issues. Many aging-regulatory genes display differences at the transcriptional level between castes in social insects, suggesting that transcriptional regulation plays crucial roles in caste-specific aging trajectories. Epigenetics connects environmental inputs with transcription and thus may be the key to the aging differences between castes (Benayoun et al., 2015). However, the interplay between many types of epigenetic mechanisms and caste-specific aging is rarely studied, although the crucial roles of histone modifications and microRNAs in establishing caste-specific transcriptional programs and caste differentiation have been proposed (Weaver et al., 2007; Bonasio et al., 2010; Spannhoff et al., 2011; Guo et al., 2013; Simola et al., 2013, 2016; Shi et al., 2015; Ashby et al., 2016; Wojciechowski et al., 2018).

\section{FLIGHT AND AGING IN INSECTS}

Metabolic rates may be related to aging and longevity. The rate of living theory proposed at the beginning of the 20th century suggests that a slowed rate of metabolism is associated with lengthened longevity (Rubner, 1916). In line with this view, recent studies revealed that increased resting metabolic rate is a risk factor for mortality in humans (Ruggiero et al., 2008; Jumpertz et al., 2011). High metabolic rates have been hypothesized to come with a cost in terms of increased level of reactive oxygen species (ROS), the byproducts of mitochondrial metabolism, which leads to accelerated aging through damaging macromolecules, including DNA, lipid, and proteins (Harman, 1956; Finkel and Holbrook, 2000). Data from humans revealed that changes in metabolic rates are accompanied by changes in oxidative stress and may underlie variation in aging rate (Redman et al., 2018). However, the relationship between metabolic rate, ROS, and lifespan is highly complex. The positive relationship between metabolic rate and ROS production provokes great debate (Speakman, 2005), and the beneficial roles of ROS in regulating lifespan, metabolism, and development have been demonstrated (Santos et al., 2018). The true mechanisms of the association between metabolic rates and aging are not well understood.

Insect flight has the highest metabolic rate (Kammer and Heinrich, 1978) and profound effects on aging process. In line with the early metabolic and locomotor senescence in Drosophila after forcing flight (Lane et al., 2014), aging is accelerated in honeybee workers after transitioning from infrequently flying nurses to frequently flying foragers (Seehuus et al., 2006a; Behrends et al., 2007). Moreover, foraging bees with flight restriction do not display aging-related learning deficits as the free-flying ones (Tolfsen et al., 2011). Flight restriction similarly decreases the mitochondrial damage and extends lifespan to approximately threefold of the normal in houseflies (Agarwal and Sohal, 1994; Yan and Sohal, 2000). These results collectively implicated the negative effects of flight on insect aging. However, flight experience is not always detrimental. For instance, flight restriction leads to increased oxidative damage in brains of honey bees and early senescence of flight performance in fruit flies (Tolfsen et al., 2011; Lane et al., 2014). A high flight activity rate within the activity days has no negative effects on longevity in two bee species in the fields (Straka et al., 2014). In Glanville fritillary butterfly (Melitaea cinxia), peak flight metabolic rates are positively associated with lifespan (Niitepõld and Hanski, 2013). Flight treatment alone has no effect on the longevity of some butterflies, including Glanville fritillary butterfly (Woestmann et al., 2017), Mormon fritillary (Speyeria mormonia) (Niitepõld and Boggs, 2015), speckled wood butterfly (Pararge aegeria) (Gibbs and Van Dyck, 2010), and squinting bush brown butterfly (Bicyclus anynana) (Saastamoinen et al., 2010). Therefore, the 
effects of flight behavior on insect longevity and aging seem to vary depending on species, flight traits, physiological states, and some other factors.

Elevated oxidative stress is considered as the primarily mechanism underlying the negative effects of flight on lifespan. In insects, flight could induce oxidative stress by increasing ROS generation from respiratory metabolism and altering membrane lipid composition that is more susceptible to ROS (Sohal et al., 1984; Yan and Sohal, 2000; Magwere et al., 2006; Williams et al., 2008; Margotta et al., 2018). Elevated oxidative stress in insects is deleterious in most cases. An increase in oxidative stress by pharmacological and genetic manipulations shortens lifespan in some insects (Phillips et al., 1989; Parkes et al., 1998; Kirby et al., 2002; Duttaroy et al., 2003; Cui et al., 2004; Margotta et al., 2018). However, the mechanism underlying the non-negative effects of insect flight on lifespan has not yet been studied. One potential explanation for these effects is that the oxidative stress generated by moderate flight may induce long-term stress response, thus protecting organisms from damage accumulation (Gems and Partridge, 2008). Another possible explanation is that some insects may evolve specific antioxidant mechanisms. For example, to resist oxidative stress during hovering flight, the tobacco hornworm (Manduca sexta) fed with nectar sugar generated antioxidant compounds by shunting glucose via lowenergy pentose phosphate pathways (Levin et al., 2017). In addition, ROS does not always play negative roles in insect longevity; it could extend longevity by inducing diapause in cotton bollworm (Helicoverpa armigera) (Zhang et al., 2017).

Studies on the mechanisms behind the effects of insect flight on aging mainly focused on oxidative stress, and few studies on other aging-regulatory mechanisms are available. Insect flight induces substantial changes in endocrine status and gene expression (Rademakers and Beenakkers, 1977; Goldsworthy, 1983; Margotta et al., 2013; Kvist et al., 2015; Woestmann et al., 2017). Whether and how these endocrine and transcriptional changes influence aging process remain elusive. Moreover, insect flight experience influences oxidative damage in a tissuedependent manner (Williams et al., 2008; Margotta et al., 2013, 2018). Flight-susceptible tissues may further affect systemic aging through inter-tissue crosstalk (Demontis et al., 2013). However, the key tissues and signals involved are still unknown. Lastly, insect species vary widely in flight traits, such as wingbeat frequency, flight duration, and wing morphology (Molloy et al., 1987; Dudley, 2002). Such variations in flight traits have effects on the differences in flight metabolic properties (Casey et al., 1985; Feller and Nachtigall, 1989; Darveau et al., 2014), and they may be involved in species variation in the effects of flight on aging through unknown mechanisms.

\section{DIAPAUSE AND AGING IN INSECTS}

How to extend lifespan has always fascinated people throughout human history. Science fictions depict that humans extend lifespan and reach the future through achieving hypometabolic states and cryonics. Interestingly, this specific ability is common in insects. Diapause, a state of programmed arrest of development coupled with suppressed metabolic activity, helps insects to survive unfavorable environmental conditions (Denlinger, 2002). During diapause, insects do not experience the same fast "aging clock" as in direct development, resulting in drastically extended lifespan (Tatar and Yin, 2001). Moreover, insects have evolved diapause at different life cycle stages, including eggs, larvae, pupae, and adults, thereby providing opportunities to study the effects of various diapause types on aging (Denlinger, 2002). Studying insect diapause could provide new insights into aging interventions and lifespan extension (Denlinger, 2008).

Insect systems demonstrate organismal and genetic links between diapause and aging. Similar with Drosophila, which undergoes a negligible senescence during reproductive diapause (Tatar et al., 2001a,b), adult monarch butterflies and grasshoppers with reproductive diapause induced by surgical removal of the corpora allata have doubled lifespan (Herman and Tatar, 2001; Tatar and Yin, 2001). In addition, a handful of evidence revealed the roles of pupal and larval diapauses on the extension of preadult longevity (Lu et al., 2013; Lin and Xu, 2016; Lin et al., 2016; Zhang et al., 2017; Wang et al., 2018). Noteworthy, diapause not only slows aging during diapause phase, but also has speciesdependent effects on adult longevity after diapause. For example, maize stalk borer (Busseola fusca) and spotted stem borer (Chilo partellus) have shortened adult lifespans after diapause (GebreAmlak, 1989; Dhillon and Hasan, 2018), but cotton bollworm (H. armigera) and multivoltine bruchid (Kytorhinus sharpianus) display extended lifespans after diapause (Ishihara and Shimada, 1995; Chen et al., 2014).

Transcriptional regulation may play a crucial role in diapause-related aging regulation (Denlinger, 2002). Several key transcription factors involved have been characterized. In the mosquito Culex pipiens, transcription factor FoxO, which is regulated by insulin and $\mathrm{JH}$ signaling, alters the expression of aging-regulatory genes during diapause (Sim and Denlinger, 2008, 2013a,b; Sim et al., 2015). In the moth $H$. armigera, accumulation of FoxO induced by high ROS activity during diapause also promote lifespan extension (Zhang et al., 2017). The diapause-related ROS increase is attributed to the downregulation of hexokinase expression, which is regulated by transcription factors CREB, c-Myc, and POU (Lin and Xu, 2016). In addition, repression of mitochondrial activity, which may be related to lifespan extension of diapause, is regulated by a network of transcription factors HIF-1 $\alpha$, CREB, Smad1, POU, and TFAM (Lin et al., 2016; Li et al., 2018; Wang et al., 2020). Except for transcription factors, epigenetic mechanism may also influence the transcriptional alterations of agingregulatory genes during diapause (Reynolds, 2017). Studies have proposed that DNA methylation (Pegoraro et al., 2016), histone modifications (Lu et al., 2013; Hickner et al., 2015; Sim et al., 2015; Reynolds et al., 2016), non-coding RNAs (Reynolds et al., 2013, 2017; Poupardin et al., 2015; Yocum et al., 2015; Reynolds, 2019), and RNA methylation (Jiang et al., 2019) may all contribute to diapause-related transcriptional changes and phenotypes. The phenomenon of extended adult lifespan after diapause in some insects suggests that the expression levels of aging-regulatory genes persist after diapause termination. The possible cause of species variation in this phenomenon is 
species-specific transcriptional maintenance. The transcriptional regulatory mechanisms underlying diapause seem to vary across insects. Interspecific comparisons revealed little transcriptional similarity among diapauses across invertebrates (Ragland et al., 2010). DNA methylation play roles in diapause regulation in the wasp Nasonia vitripennis but not in the silkmoth Bombyx mori (Pegoraro et al., 2016; Yuichi et al., 2016).

Some gaps exist in understanding the effects of diapause on aging. Although a great variation in the expression of aging-related genes during diapause has been documented, experimental evidence of cause-and-effect relationships between gene expression and aging is still lacking. Moreover, whether the expression levels of these diapause-induced aging-regulatory genes persist after diapause termination and the underlying mechanisms involved are unclear.

\section{CONCLUSION AND PERSPECTIVE}

Substantial progress has been achieved in enhancing the understanding of the molecular basis of aging regulation in insect aging. Obviously, these underlying molecular mechanisms were highly intertwined processes. Transcriptional differences are the most observed differences in aging-regulatory genes involved in endocrine regulation, oxidative stress responses, maintenance of telomere, and genomic stability (Amdam et al., 2005; Corona et al., 2007; Bonasio et al., 2010; Elsner et al., 2018). These transcriptional differences may be attributed to variations in transcription factors and epigenetic states, which in turn are influenced by endocrine factors (Sim and Denlinger, 2008, 2013a; Vaiserman et al., 2018). The mechanisms mentioned above also play critical roles in mammalian and human aging (Lopez-Otin et al., 2013). For instance, reduced insulin signaling is related to extended longevity in social insects and mammals (Tatar et al., 2003; Corona et al., 2007; Ament et al., 2008), although the insulin pathways considerably vary across species (Corona et al., 2007; Smýkal et al., 2020). DNA methylation is closely related to aging from insects to mammals (Herb et al., 2012; Yan et al., 2015; Horvath and Raj, 2018), although the differences in genomic DNA methylation between insects and vertebrates are highly significant (de Mendoza et al., 2020). This finding suggests that aging-regulatory pathways are evolutionarily conserved, although the detailed mechanisms may vary across species. Thus, aging studies on non-Drosophila insects could expand the understanding of aging regulators and help develop anti-aging

\section{REFERENCES}

Agarwal, S., and Sohal, R. S. (1994). DNA oxidative damage and life expectancy in houseflies. Proc. Natl. Acad. Sci. U S A. 91, 12332-12335. doi: 10.1073/pnas.91. 25.12332

Amdam, G. V., Aase, A. L. T. O., Seehuus, S.-C., Kim Fondrk, M., Norberg, K., and Hartfelder, K. (2005). Social reversal of immunosenescence in honey bee workers. Exp. Gerontol. 40, 939-947. doi: 10.1016/j.exger.2005.08.004

Ament, S. A., Corona, M., Pollock, H. S., and Robinson, G. E. (2008). Insulin signaling is involved in the regulation of worker division of labor in honey interventions. Here, several perspectives for further studies on insect aging are provided as follows.

First, studying the aging mechanisms underlying aging plasticity in non-social insects is highly valuable. Transcription regulation represents one of the key mechanisms underlying aging regulation, and it is the downstream of environmentinduced epigenetic changes. Thus, transcriptome analysis could be used to screen key aging genes and pathways underlying aging plasticity in these species.

Second, determining epigenetic mechanisms underlying aging plasticity is essential. A large number of studies suggest that epigenetic factors have potential roles in aging regulation in polyphenic insects. Epigenetic marks are plastic, and many drugs targeting epigenetic enzymes are available (Heerboth et al., 2014). Investigating the link between epigenetic information and environment cues and the epigenetic mechanisms behind insect aging could provide new insights into treatments for aging retardation and reversal.

Third, the effects of insect flight and diapause on aging vary largely depending on insect species. The diversity of insects offers rich resources for cross-species comparisons. Thus, interspecific analysis could help elucidate the mechanisms underlying the beneficial effects of insect flight and diapause on adult longevity, which may reveal new strategies to prevent collapse during aging.

Thousands of insect genomes have been sequenced ( $\mathrm{Li}$ et al., 2019), and gene editing tools have been developed in various insects (Gantz and Akbari, 2018; Hillary et al., 2020). A strong and growing arsenal of powerful technologies provides a huge support for elucidating the molecular mechanisms underlying insect aging. These novel insect models are expected to result in groundbreaking discoveries and ultimately promote human healthy aging in the future.

\section{AUTHOR CONTRIBUTIONS}

LK and XW designed the research. SG collected the references. SG, LK, and XW wrote the manuscript. All authors contributed to the article and approved the submitted version.

\section{FUNDING}

This study was supported by the National Natural Science Foundation of China (Grant Nos. 31920103004, 31930012, and 31772531).

bee colonies. Proc. Natl. Acad. Sci. U S A. 105, 4226-4231. doi: 10.1073/pnas. 0800630105

Ashby, R., Forêt, S., Searle, I., and Maleszka, R. (2016). MicroRNAs in honey bee caste determination. Sci. Rep. 6:18794. doi: 10.1038/srep18794

Baker, N., Wolschin, F., and Amdam, G. V. (2012). Age-related learning deficits can be reversible in honeybees Apis mellifera. Exp. Gerontol. 47, 764-772. doi: 10.1016/j.exger.2012.05.011

Behrends, A., Scheiner, R., Baker, N., and Amdam, G. V. (2007). Cognitive aging is linked to social role in honey bees (Apis mellifera). Exp. Gerontol. 42, 1146-1153. doi: 10.1016/j.exger.2007.09.003 
Benayoun, B. A., Pollina, E. A., and Brunet, A. (2015). Epigenetic regulation of ageing: linking environmental inputs to genomic stability. Nat. Rev. Mol. Cell Bio. 16, 593-610. doi: 10.1038/nrm4048

Bloch, G., Wheeler, D. E., and Robinson, G. E. (2002). "Endocrine influences on the organization of insect societies," in Hormones Brain and Behavior, D.W. Pfaff, A.P. Arnold, A.M. Etgen, S.E. Fahrbach \& R.T. Rubin, (San Diego: Academic Press), 1027-1068. doi: 10.1016/b978-008088783-8.00030-9

Boerjan, B., Sas, F., Ernst, U. R., Tobback, J., Lemiere, F., Vandegehuchte, M. B., et al. (2011). Locust phase polyphenism: Does epigenetic precede endocrine regulation? Gen. Comp. Endocr. 173, 120-128. doi: 10.1016/j.ygcen.2011. 05.003

Bonasio, R., Li, Q., Lian, J., Mutti, N. S., Jin, L., Zhao, H., et al. (2012). Genomewide and caste-specific DNA methylomes of the ants Camponotus floridanus and Harpegnathos saltator. Curr. Biol. 22, 1755-1764. doi: 10.1016/j.cub.2012. 07.042

Bonasio, R., Zhang, G., Ye, C., Mutti, N. S., Fang, X., Qin, N., et al. (2010). Genomic Comparison of the Ants Camponotus floridanus and Harpegnathos saltator. Science 329, 1068-1071. doi: 10.1126/science.1192428

Brunner, E., Kroiss, J., Trindl, A., and Heinze, J. (2011). Queen pheromones in Temnothorax ants: control or honest signal? BMC Evol. Biol. 11:55. doi: 10. 1186/1471-2148-11-55

Cardoso-Júnior, C. A. M., Guidugli-Lazzarini, K. R., and Hartfelder, K. (2018). DNA methylation affects the lifespan of honey bee (Apis mellifera L.) workers - Evidence for a regulatory module that involves vitellogenin expression but is independent of juvenile hormone function. Insect. Biochem. Mol. Biol. 92, 21-29. doi: 10.1016/j.ibmb.2017.11.005

Casey, T. M., May, M. L., and Morgan, K. R. (1985). Flight energetics of euglossine bees in relation to morphology and wing stroke frequency. J. Exp. Biol. 116, 271-289.

Chen, C., Xia, Q., Xiao, H., Xiao, L., and Xue, F. (2014). A comparison of the life-history traits between diapause and direct development individuals in the cotton bollworm, Helicoverpa armigera. J. Insect. Sci. 14:19. doi: 10.1093/jis/14. 1.19

Corona, M., Hughes, K. A., Weaver, D. B., and Robinson, G. E. (2005). Gene expression patterns associated with queen honey bee longevity. Mech. Age. Dev. 126, 1230-1238. doi: 10.1016/j.mad.2005.07.004

Corona, M., Velarde, R. A., Remolina, S., Moran-Lauter, A., Wang, Y., Hughes, K. A., et al. (2007). Vitellogenin, juvenile hormone, insulin signaling, and queen honey bee longevity. Proc. Natl. Acad. Sci. U S A. 104, 7128-7133. doi: 10.1073/ pnas.0701909104

Cui, X., Wang, L., Zuo, P., Han, Z., Fang, Z., Li, W., et al. (2004). D-Galactosecaused life shortening in Drosophila melanogaster and Musca domestica is associated with oxidative stress. Biogerontology 5, 317-325. doi: 10.1007/ s10522-004-2570-3

Darveau, C.-A., Billardon, F., and Bélanger, K. (2014). Intraspecific variation in flight metabolic rate in the bumblebee Bombus impatiens repeatability and functional determinants in workers and drones. J. Exp. Biol. 217, 536-544. doi: 10.1242/jeb.091892

de Mendoza, A., Lister, R., and Bogdanovic, O. (2020). Evolution of DNA methylome diversity in eukaryotes. J. Mol. Biol. 432, 1687-1705. doi: 10.1016/j. jmb.2019.11.003

Demontis, F., Piccirillo, R., Goldberg, A. L., and Perrimon, N. (2013). The influence of skeletal muscle on systemic aging and lifespan. Aging Cell 12, 943-949. doi: 10.1111 /acel.12126

Denlinger, D. L. (2002). Regulation of diapause. Annu. Rev. Entomol. 47, 93-122. doi: 10.1146/annurev.ento.47.091201.145137

Denlinger, D. L. (2008). Why study diapause? Entomol. Res. 38, 1-9. doi: 10.1111/j. 1748-5967.2008.00139.x

Dhillon, M. K., and Hasan, F. (2018). Consequences of diapause on postdiapause development, reproductive physiology and population growth of Chilo partellus (Swinhoe). Physiol. Entomol. 43, 196-206. doi: 10.1111/phen. 12243

Dudley, R. (2002). The biomechanics of insect flight: form, function, evolution. Princeton, NJ: Princeton University Press, doi: 10.1515/9780691186344

Duggal, N. A., Pollock, R. D., Lazarus, N. R., Harridge, S., and Lord, J. M. (2018). Major features of immunesenescence, including reduced thymic output, are ameliorated by high levels of physical activity in adulthood. Aging Cell 17:e12750. doi: 10.1111/acel.12750
Duttaroy, A., Paul, A., Kundu, M., and Belton, A. (2003). A Sod2 null mutation confers severely reduced adult life span in Drosophila. Genetics 165, 2295-2299.

Elsner, D., Meusemann, K., and Korb, J. (2018). Longevity and transposon defense, the case of termite reproductives. Proc. Natl. Acad. Sci. U S A. 115, 5504-5509. doi: 10.1073 /pnas. 1804046115

Feller, P., and Nachtigall, W. (1989). Flight of the honey bee. J. Comp. Physio. B 158, 719-727.

Finkel, T., and Holbrook, N. J. (2000). Oxidants, oxidative stress and the biology of ageing. Nature 408, 239-247. doi: 10.1038/35041687

Foret, S., Kucharski, R., Pellegrini, M., Feng, S., Jacobsen, S. E., Robinson, G. E., et al. (2012). DNA methylation dynamics, metabolic fluxes, gene splicing, and alternative phenotypes in honey bees. Proc. Natl. Acad. Sci. U S A 109, 4968-4973. doi: 10.1073/pnas.1202392109

Freitak, D., Tammaru, T., Sandre, S.-L., Meister, H., and Esperk, T. (2019). Longer life span is associated with elevated immune activity in a seasonally polyphenic butterfly. J. Evol. Biol. 32, 653-665. doi: 10.1111/jeb.13445

Gantz, V. M., and Akbari, O. S. (2018). Gene editing technologies and applications for insects. Curr. Opin. Insect. Sci. 28, 66-72. doi: 10.1016/j.cois.2018.05.006

Gebre-Amlak, A. (1989). Phenology and fecundity of maize stalk borer Busseola fusca (Fuller) in Awassa. South. Ethiopia. Insect. Sci. Appl. 10, 131-137. doi: $10.1017 / \mathrm{s} 1742758400010274$

Gems, D., and Partridge, L. (2008). Stress-response hormesis and aging: "that which does not kill us makes us stronger". Cell Metab. 7, 200-203. doi: 10.1016/j.cmet. 2008.01.001

Gibbs, M., and Van Dyck, H. (2010). Butterfly flight activity affects reproductive performance and longevity relative to landscape structure. Oecologia 163, 341-350. doi: 10.1007/s00442-010-1613-5

Goldsworthy, G. J. (1983). The endocrine control of flight metabolism in locusts. Adv. Insect. Physiol. 17, 149-204. doi: 10.1016/S0065-2806(08)60218-0

Guidugli, K. R., Nascimento, A. M., Amdam, G. V., Barchuk, A. R., Omholt, S., Simões, Z. L. P., et al. (2005). Vitellogenin regulates hormonal dynamics in the worker caste of a eusocial insect. FEBS Lett. 579, 4961-4965. doi: 10.1016/j. febslet.2005.07.085

Guo, M. (2012). Drosophila as a model to study mitochondrial dysfunction in Parkinson's disease. Cold Spring Harb. Perspect Med. 2:a009944. doi: 10.1101/ cshperspect.a009944

Guo, X., Su, S., Skogerboe, G., Dai, S., Li, W., Li, Z., et al. (2013). Recipe for a busy bee: microRNAs in honey bee caste determination. PLoS One 8:e81661. doi: 10.1371/journal.pone.0081661

Haddad, L. S., Kelbert, L., and Hulbert, A. J. (2007). Extended longevity of queen honey bees compared to workers is associated with peroxidation-resistant membranes. Exp. Gerontol. 42, 601-609. doi: 10.1016/j.exger.2007.02.008

Hahn, D. A., and Denlinger, D. L. (2010). Energetics of insect diapause. Annu. Rev. Entomol. 56, 103-121. doi: 10.1146/annurev-ento-112408-085436

Harman, D. (1956). Aging: a theory based on free radical and radiation chemistry. J. Gerontol. 11, 298-300. doi: 10.1093/geronj/11.3.298

Hartmann, A., and Heinze, J. (2003). Lay eggs, live longer: division of labor and life span in a clonal ant species. Evolution 57, 2424-2429. doi: 10.1111/j.0014-3820. 2003.tb00254.x

He, W., Goodkind, D., and Kowal, P. (2016). An Aging World: 2015. International Population Reports. Suitland, MA: United States Census Bureau, doi: 10.1007/ 978-3-642-19335-4_63

Heerboth, S., Lapinska, K., Snyder, N., Leary, M., Rollinson, S., and Sarkar, S. (2014). Use of epigenetic drugs in disease: An overview. Genet. Epigenet 1, 9-19. doi: 10.4137/GEG.S12270

Helfand, S. L., and Rogina, B. (2003). Genetics of aging in the fruit fly. Drosophila melanogaster. Annu. Rev. Genet 37, 329-348. doi: 10.1146/annurev.genet.37. 040103.095211

Herb, B. R., Wolschin, F., Hansen, K. D., Aryee, M. J., Langmead, B., Irizarry, R., et al. (2012). Reversible switching between epigenetic states in honeybee behavioral subcastes. Nat. Neurosci. 15, 1371-1373. doi: 10.1038/nn.3218

Herman, W. S., and Tatar, M. (2001). Juvenile hormone regulation of longevity in the migratory monarch butterfly. Proc. Biol. Sci. 268, 2509-2514. doi: 10.1098/ rspb.2001.1765

Herskind, A. M., Mcgue, M., Holm, N. V., Sorensen, T. I. A., Harvald, B., and Vaupel, J. W. (1996). The heritability of human longevity: A population-based study of 2872 Danish twin pairs born 1870-1900. Hum. Genet 97, 319-323. doi: $10.1007 / \mathrm{BF} 02185763$ 
Hickner, P. V., Mori, A., Zeng, E., Tan, J. C., and Severson, D. W. (2015). Whole transcriptome responses among females of the filariasis and arbovirus vector mosquito Culex pipiens implicate TGF- $\beta$ signaling and chromatin modification as key drivers of diapause induction. Funct. Integr. Genom. 15, 439-447. doi: 10.1007/s10142-015-0432-5

Hillary, V. E., Ceasar, S. A., and Ignacimuthu, S. (2020). "Genome engineering in insects: focus on the CRISPR/Cas9 system," in Genome Engineering via CRISPR-Cas9 System, eds V. Singh and P. K. Dhar (Academic Press), 219-249. doi: 10.1016/B978-0-12-818140-9.00018-0

Hölldobler, B., and Wilson, E. O. (1990). The ants. Cambridge, MA: Belknap Press of Harvard University Press.

Horvath, S., and Raj, K. (2018). DNA methylation-based biomarkers and the epigenetic clock theory of ageing. Nat. Rev. Genet. 19, 371-384. doi: 10.1038/ s41576-018-0004-3

Ishihara, M., and Shimada, M. (1995). Trade-off in allocation of metabolic reserves: effects of diapause on egg production and adult longevity in a multivotine bruchid. Kytorhinus sharpianus. Funct. Ecol. 9, 618-624. doi: 10.2307/2390152

Jiang, T., Li, J., Qian, P., Xue, P., Xu, J., Chen, Y., et al. (2019). The role of N6-methyladenosine modification on diapause in silkworm (Bombyx mori) strains that exhibit different voltinism. Mol. Reprod. Dev. 86, 1981-1992. doi: $10.1002 / \operatorname{mrd} .23283$

Jumpertz, R., Hanson, R. L., Sievers, M. L., Bennett, P. H., Nelson, R. G., and Krakoff, J. (2011). Higher energy expenditure in humans predicts natural mortality. J. Clin. Endocrinol. Metab. 96, E972-E976. doi: 10.1210/jc.2010-2944

Kammer, A. E., and Heinrich, B. (1978). Insect flight metabolism. Adv. Insect. Phys. 13, 133-228. doi: 10.1016/S0065-2806(08)60266-0

Keller, L., and Jemielity, S. (2006). Social insects as a model to study the molecular basis of ageing. Exp. Gerontol. 41, 553-556. doi: 10.1016/j.exger.2006.04.002

Kennedy, B. K., Berger, S. L., Brunet, A., Campisi, J., Cuervo, A. M., Epel, E. S., et al. (2014). Geroscience: linking aging to chronic disease. Cell 159, 708-712. doi: 10.1016/j.cell.2014.10.039

Kirby, K., Hu, J., Hilliker, A. J., and Phillips, J. P. (2002). RNA interferencemediated silencing of Sod2 in Drosophila leads to early adult-onset mortality and elevated endogenous oxidative stress. Proc. Natl. Acad. Sci. U S A. 99, 16162-16167. doi: 10.1073/pnas.252342899

Kohlmeier, P., Negroni, M. A., Kever, M., Emmling, S., Stypa, H., Feldmeyer, B., et al. (2017). Intrinsic worker mortality depends on behavioral caste and the queens' presence in a social insect. Sci. Nat. 104:34. doi: 10.1007/s00114-0171452-x

Korandová, M., and Frydrychová, R. Č. (2016). Activity of telomerase and telomeric length in Apis mellifera. Chromosoma 125, 405-411. doi: 10.1007/ s00412-015-0547-4

Kramer, B. H., and Schaible, R. (2013). Colony size explains the lifespan differences between queens and workers in eusocial Hymenoptera. Biol. J. Linn. Soc. 109, 710-724. doi: 10.1111/bij.12072

Kramer, B. H., Van Doorn, G. S., Weissing, F. J., and Pen, I. (2016). Lifespan divergence between social insect castes: challenges and opportunities for evolutionary theories of aging. Curr. Opin. Insect. Sci. 16, 76-80. doi: 10.1016/j. cois.2016.05.012

Krutmann, J., Bouloc, A., Sore, G., Bernard, B. A., and Passeron, T. (2017). The skin aging exposome. J. Dermatol. Sci. 85, 152-161. doi: 10.1016/j.jdermsci.2016. 09.015

Kvist, J., Mattila, A. L. K., Somervuo, P., Ahola, V., Koskinen, P., Paulin, L., et al. (2015). Flight-induced changes in gene expression in the Glanville fritillary butterfly. Mol. Ecol. 24, 4886-4900. doi: 10.1111/mec.13359

Lane, S. J., Frankino, W. A., Elekonich, M. M., and Roberts, S. P. (2014). The effects of age and lifetime flight behavior on flight capacity in Drosophila melanogaster. J. Exp. Biol. 217, 1437-1443. doi: 10.1242/jeb.095646

Le Bourg, E. (2001). Oxidative stress, aging and longevity in Drosophila melanogaster. FEBS Lett. 498, 183-186. doi: 10.1016/s0014-5793(01)02457-7

Levin, E., Lopez-Martinez, G., Fane, B., and Davidowitz, G. (2017). Hawkmoths use nectar sugar to reduce oxidative damage from flight. Science 355, 733-734. doi: 10.1126/science.aah4634

Li, F., Zhao, X., Li, M., He, K., Huang, C., Zhou, Y., et al. (2019). Insect genomes: progress and challenges. Insect. Mol. Biol. 28, 739-758. doi: 10.1111/imb.12599

Li, H., Lin, X., Geng, S., and Xu, W. (2018). TGF- $\beta$ and BMP signals regulate insect diapause through Smad1-POU-TFAM pathway. Biochim. Biophys. Acta Mol. Cell Res. 1865, 1239-1249. doi: 10.1016/j.bbamcr.2018.06.002
Li, W., Prazak, L., Chatterjee, N., Grüninger, S., Krug, L., Theodorou, D., et al. (2013). Activation of transposable elements during aging and neuronal decline in Drosophila. Nat. Neurosci. 16, 529-531. doi: 10.1038/nn.3368

Lin, X., Tang, L., Yang, J., and Xu, W. (2016). HIF-1 regulates insect lifespan extension by inhibiting c-Myc-TFAM signaling and mitochondrial biogenesis. Biochim. Biophys. Acta Mol. Cell Res. 1863, 2594-2603. doi: 10.1016/j.bbamcr. 2016.07.007

Lin, X., and Xu, W. (2016). Hexokinase is a key regulator of energy metabolism and ROS activity in insect lifespan extension. Aging 8, 245-259. doi: 10.18632/aging. 100885

Lopez-Otin, C., Blasco, M. A., Partridge, L., Serrano, M., and Kroemer, G. (2013). The hallmarks of aging. Cell 153, 1194-1217. doi: 10.1016/j.cell.2013. 05.039

Lopez-Otin, C., Galluzzi, L., Freije, J. M. P., Madeo, F., and Kroemer, G. (2016). Metabolic Control of Longevity. Cell 166, 802-821. doi: 10.1016/j.cell.2016. 07.031

Lu, Y., Denlinger, D. L., and Xu, W. (2013). Polycomb repressive complex 2 (PRC2) protein ESC regulates insect developmental timing by mediating H3K27me3 and activating prothoracicotropic hormone gene expression. J. Biol. Chem. 288, 23554-23564. doi: 10.1074/jbc.M113.482497

Magwere, T., Pamplona, R., Miwa, S., Martinez-Diaz, P., Portero-Otin, M., Brand, M. D., et al. (2006). Flight activity, mortality rates, and lipoxidative damage in Drosophila. J. Gerontol. A Biol. Sci. Med. Sci. 61, 136-145. doi: 10.1093/gerona/ 61.2.136

Marco, A., Hui, J. H. L., Ronshaugen, M., and Griffiths-Jones, S. (2010). Functional shifts in insect microRNA evolution. Genome Biol. Evol. 2, 686-696. doi: 10. 1093/gbe/evq053

Margotta, J. W., Mancinelli, G. E., Benito, A. A., Ammons, A., Roberts, S. P., and Elekonich, M. M. (2013). Effects of flight on gene expression and aging in the honey bee brain and flight muscle. Insects 4, 9-30. doi: 10.3390/insects4010009

Margotta, J. W., Roberts, S. P., and Elekonich, M. M. (2018). Effects of flight activity and age on oxidative damage in the honey bee, Apis mellifera. J. Exp. Biol. 221:jeb183228. doi: 10.1242/jeb.183228

Martin, N., Hulbert, A. J., Brenner, G. C., Brown, S. H. J., Mitchell, T. W., and Else, P. L. (2019). Honey bee caste lipidomics in relation to life-history stage and the long life of the queen. J. Exp. Biol. 222:jeb207043. doi: 10.1242/jeb.207043

Mayhew, P. J. (2007). Why are there so many insect species? Perspectives from fossils and phylogenies. Biol. Rev. 82, 425-454. doi: 10.1111/j.1469-185X.2007. 00018.x

Molloy, J., Kyrtatas, V., Sparrow, J., and White, D. (1987). Kinetics of flight muscles from insects with different wingbeat frequencies. Nature 328, 449-451. doi: 10.1038/328449a0

Münch, D., and Amdam, G. V. (2010). The curious case of aging plasticity in honey bees. FEBS Lett. 584, 2496-2503. doi: 10.1016/j.febslet.2010.04.007

Münch, D., Amdam, G. V., and Wolschin, F. (2008). Ageing in a eusocial insect: molecular and physiological characteristics of life span plasticity in the honey bee. Funct. Ecol. 22, 407-421. doi: 10.1111/j.1365-2435.2008.01419.x

Niitepõld, K., and Boggs, C. L. (2015). Effects of increased flight on the energetics and life history of the butterfly Speyeria mormonia. PLoS One 10:e140104. doi: 10.1371/journal.pone.0140104

Niitepõld, K., and Hanski, I. (2013). A long life in the fast lane: positive association between peak metabolic rate and lifespan in a butterfly. J. Exp. Biol. 216, 1388-1397. doi: 10.1242/jeb.080739

Nunes, F. M. F., Ihle, K. E., Mutti, N. S., Simões, Z. L. P., and Amdam, G. V. (2013). The gene vitellogenin affects microRNA regulation in honey bee Apis mellifera fat body and brain. J. Exp. Biol. 216, 3724-3732. doi: 10.1242/jeb.089243

Ogawa, K., and Miura, T. (2014). Aphid polyphenisms: trans-generational developmental regulation through viviparity. Front. Physiol. 5:1. doi: 10.3389/ fphys.2014.00001

Page, R. E. Jr., and Amdam, G. V. (2007). The making of a social insect: developmental architectures of social design. BioEssays 29, 334-343. doi: 10. 1002/bies.20549

Parker, J. D., Parker, K. M., Sohal, B. H., Sohal, R. S., and Keller, L. (2004). Decreased expression of $\mathrm{Cu}-\mathrm{Zn}$ superoxide dismutase 1 in ants with extreme lifespan. Proc. Natl. Acad. Sci. U S A. 101, 3486-3489. doi: 10.1073/pnas.0400222101

Parkes, T., Kirby, K., Phillips, J., and Hilliker, A. (1998). Transgenic analysis of the cSOD-null phenotypic syndrome in Drosophila. Genome 41, 642-651. doi: $10.1139 / g 98-068$ 
Pegoraro, M., Bafna, A., Davies, N. J., Shuker, D. M., and Tauber, E. (2016). DNA methylation changes induced by long and short photoperiods in Nasonia. Gen. Res. 26, 203-210. doi: 10.1101/gr.196204.115

Pener, M. P., and Simpson, S. J. (2009). Locust phase polyphenism: an update. $A d v$. Insect. Phys. 36, 1-272. doi: 10.1016/S0065-2806(08)36001-9

Phillips, J. P., Campbell, S. D., Michaud, D., Charbonneau, M., and Hilliker, A. J. (1989). Null mutation of copper-zinc superoxide-dismutase in Drosophila confers hypersensitivity to paraquat and reduced Longevity. Proc. Natl. Acad. Sci. U S A. 86, 2761-2765. doi: 10.1073/pnas.86.8.2761

Piper, M. D. W., and Partridge, L. (2018). Drosophila as a model for ageing. Biochim. Biophys. Acta Mol. Basis Dis. 1864, 2707-2717. doi: 10.1016/j.bbadis. 2017.09.016

Poupardin, R., Schöttner, K., Korbelová, J., Provazník, J., Doležel, D., Pavlinic, D., et al. (2015). Early transcriptional events linked to induction of diapause revealed by RNAseq in larvae of drosophilid fly, Chymomyza costata. BMC Genomics 16:720. doi: 10.1186/s12864-015-1907-4

Quigley, T. P., Amdam, G. V., and Rueppell, O. (2018). "Honeybee Workers as Models of Aging," in Conn's Handbook of Models for Human Aging (Second Edition), eds J. L. Ram and P. M. Conn (Cambridage: Academic Press), 533-547. doi: 10.1016/b978-0-12-811353-0.00040-3

Rademakers, L. H. P. M., and Beenakkers, A. M. T. (1977). Changes in the secretory activity of the glandular lobe of the corpus cardiacum of Locusta migratoria induced by flight. Cell Tissue Res. 180, 155-171. doi: 10.1007/BF00231949

Ragland, G. J., Denlinger, D. L., and Hahn, D. A. (2010). Mechanisms of suspended animation are revealed by transcript profiling of diapause in the flesh fly. Proc. Natl. Acad. Sci. U S A. 107, 14909-14914. doi: 10.1073/pnas.1007075107

Redman, L. M., Smith, S. R., Burton, J. H., Martin, C. K., Il'yasova, D., and Ravussin, E. (2018). Metabolic slowing and reduced oxidative damage with sustained caloric restriction support the rate of living and oxidative damage theories of aging. Cell Metab. 27, 805-815. doi: 10.1016/j.cmet.2018.02.019

Reiter, L. T., Potocki, L., Chien, S., Gribskov, M., and Bier, E. (2001). A systematic analysis of human disease-associated gene sequences in Drosophila melanogaster. Genome Res. 11, 1114-1125. doi: 10.1101/gr.169101

Remolina, S. C., and Hughes, K. A. (2008). Evolution and mechanisms of long life and high fertility in queen honey bees. Age 30:177. doi: 10.1007/s11357-0089061-4

Reynolds, J. A. (2017). Epigenetic influences on diapause. Adv Insect Phys. 53, 115-144. doi: 10.1016/bs.aiip.2017.03.003

Reynolds, J. A. (2019). Noncoding RNA regulation of dormant states in evolutionarily diverse animals. Biol. Bull. 237, 192-209. doi: 10.1086/705484

Reynolds, J. A., Bautista-Jimenez, R., and Denlinger, D. L. (2016). Changes in histone acetylation as potential mediators of pupal diapause in the flesh fly, Sarcophaga bullata. Insect. Biochem. Mol. Biol. 76, 29-37. doi: 10.1016/j.ibmb. 2016.06.012

Reynolds, J. A., Clark, J., Diakoff, S. J., and Denlinger, D. L. (2013). Transcriptional evidence for small RNA regulation of pupal diapause in the flesh fly, Sarcophaga bullata. Insect. Biochem. Mol. Biol. 43, 982-989. doi: 10.1016/j.ibmb.2013. 07.005

Reynolds, J. A., Peyton, J. T., and Denlinger, D. L. (2017). Changes in microRNA abundance may regulate diapause in the flesh fly, Sarcophaga bullata. Insect. Biochem. Mol. Biol. 84, 1-14. doi: 10.1016/j.ibmb.2017.03.002

Robinson, G. E., and Vargo, E. L. (1997). Juvenile hormone in adult eusocial Hymenoptera: gonadotropin and behavioral pacemaker. Arch. Insect. Biochem. Physiol. 35, 559-583. doi: 10.1002/(sici)1520-6327(1997)35:4<559::aid-arch13> 3.0.co;2-9

Rodrigues, M. A., and Flatt, T. (2016). Endocrine uncoupling of the trade-off between reproduction and somatic maintenance in eusocial insects. Curr. Opin. Insect. Sci. 16, 1-8. doi: 10.1016/j.cois.2016.04.013

Rubner, M. (1916). Machinery of metabolism. JAMA 66:1879. doi: 10.1111/jgs. 12740

Ruggiero, C., Metter, E. J., Melenovsky, V., Cherubini, A., Najjar, S. S., Ble, A., et al. (2008). High basal metabolic rate is a risk factor for mortality: the Baltimore Longitudinal Study of Aging. J. Gerontol. A Biol. Sci. Med. Sci. 63, 698-706. doi: 10.1093/gerona/63.7.698

Saastamoinen, M., Van Der Sterren, D., Vastenhout, N., Zwaan, B. J., and Brakefield, P. M. (2010). Predictive adaptive responses: condition-dependent impact of adult nutrition and flight in the tropical butterfly Bicyclus anynana. Am. Nat. 176, 686-698. doi: 10.1086/657038
Santos, A. L., Sinha, S., and Lindner, A. B. (2018). The good, the bad, and the ugly of ROS: new insights on aging and aging-related diseases from eukaryotic and prokaryotic model organisms. Oxid. Med. Cell Longev. 2018:1941285. doi: $10.1155 / 2018 / 1941285$

Schneider, S. A., Schrader, C., Wagner, A. E., Boesch-Saadatmandi, C., Liebig, J., Rimbach, G., et al. (2011). Stress resistance and longevity are not directly linked to levels of enzymatic antioxidants in the ponerine ant Harpegnathos saltator. PLoS One 6:e14601. doi: 10.1371/journal.pone.0014601

Sebastiani, P., and Perls, T. T. (2012). The genetics of extreme longevity: lessons from the new England centenarian study. Front. Genet. 3:277. doi: 10.3389/ fgene.2012.00277

Seehuus, S.-C., Krekling, T., and Amdam, G. V. (2006a). Cellular senescence in honey bee brain is largely independent of chronological age. Exp. Gerontol. 41, 1117-1125. doi: 10.1016/j.exger.2006.08.004

Seehuus, S.-C., Norberg, K., Gimsa, U., Krekling, T., and Amdam, G. V. (2006b). Reproductive protein protects functionally sterile honey bee workers from oxidative stress. Proc. Natl. Acad. Sci. U S A. 103, 962-967. doi: 10.1073/pnas. 0502681103

Seeley, T. D. (1978). Life history strategy of the honey bee, Apis mellifera. Oecologia 32, 109-118. doi: 10.1007/BF00344695

Shi, Y., Zheng, H., Pan, Q., Wang, Z., and Zeng, Z. (2015). Differentially expressed microRNAs between queen and worker larvae of the honey bee (Apis mellifera). Apidologie 46, 35-45. doi: 10.1007/s13592-014-0299-9

Sim, C., and Denlinger, D. L. (2008). Insulin signaling and FOXO regulate the overwintering diapause of the mosquito Culex pipiens. Proc. Natl. Acad. Sci. U S A. 105, 6777-6781. doi: 10.1073/pnas.0802067105

Sim, C., and Denlinger, D. L. (2013a). Juvenile hormone III suppresses forkhead of transcription factor in the fat body and reduces fat accumulation in the diapausing mosquito, Culex pipiens. Insect. Mol. Biol. 22, 1-11. doi: 10.1111/ j.1365-2583.2012.01166.x

Sim, C., and Denlinger, D. L. (2013b). Insulin signaling and the regulation of insect diapause. Front. Physiol. 4:189. doi: 10.3389/fphys.2013.00189

Sim, C., Kang, D. S., Kim, S., Bai, X., and Denlinger, D. L. (2015). Identification of FOXO targets that generate diverse features of the diapause phenotype in the mosquito Culex pipiens. Proc. Natl. Acad. Sci. U S A 112, 3811-3816. doi: 10.1073/pnas.1502751112

Simola, D. F., Graham, R. J., Brady, C. M., Enzmann, B. L., Desplan, C., Ray, A., et al. (2016). Epigenetic (re)programming of caste-specific behavior in the ant Camponotus floridanus. Science 351:aac6633. doi: 10.1126/science.aac 6633

Simola, D. F., Ye, C., Mutti, N. S., Dolezal, K., Bonasio, R., Liebig, J., et al. (2013). A chromatin link to caste identity in the carpenter ant Camponotus floridanus. Gen. Res. 23, 486-496. doi: 10.1101/gr.148361.112

Simpson, S. J., Sword, G. A., and Lo, N. (2011). Polyphenism in insects. Curr. Biol. 21, R738-R749. doi: 10.1016/j.cub.2011.06.006

Smýkal, V., Pivarči, M., Provazník, J., Bazalová, O., Jedlička, P., Lukšan, O., et al. (2020). Complex evolution of insect insulin receptors and homologous decoy receptors, and functional significance of their multiplicity. Mol. Biol. Evol. 37, 1775-1789. doi: 10.1093/molbev/msaa048

Sohal, R., Allen, R., Farmer, K., and Procter, J. (1984). Effect of physical activity on superoxide dismutase, catalase, inorganic peroxides and glutathione in the adult male housefly, Musca domestica. Mech. Age. Dev. 26, 75-81. doi: 10.1016/ 0047-6374(84)90069-1

Solovev, I., Shaposhnikov, M., Kudryavtseva, A., and Moskalev, A. (2018). "Drosophila melanogaster as a model for studying the epigenetic basis of aging," in Epigenetics of Aging and Longevity, eds A. Moskalev and A. M. Vaiserman (Boston: Academic Press), 293-307. doi: 10.1016/b978-0-12-811060-7.00 014-0

Spannhoff, A., Kim, Y. K., Raynal, N. J. M., Gharibyan, V., Su, M., Zhou, Y., et al. (2011). Histone deacetylase inhibitor activity in royal jelly might facilitate caste switching in bees. EMBO Rep. 12, 238-243. doi: 10.1038/embor.2011.9

Speakman, J. R. (2005). Body size, energy metabolism and lifespan. J. Exp. Biol. 208, 1717-1730. doi: 10.1242/jeb.01556

Straka, J., černá, K., Macháčková, L., Zemenová, M., and Keil, P. (2014). Life span in the wild: the role of activity and climate in natural populations of bees. Funct. Ecol. 28, 1235-1244. doi: 10.1111/1365-2435.12261

Tatar, M., Bartke, A., and Antebi, A. (2003). The endocrine regulation of aging by insulin-like signals. Science 299, 1346-1351. doi: 10.1126/science.1081447 
Tatar, M., Chien, S. A., and Priest, N. K. (2001a). Negligible senescence during reproductive dormancy in Drosophila melanogaster. Am. Nat. 158, 248-258. doi: $10.1086 / 321320$

Tatar, M., Kopelman, A., Epstein, D., Tu, M. P., Yin, C. M., and Garofalo, R. S. (2001b). A mutant Drosophila insulin receptor homolog that extends life-span and impairs neuroendocrine function. Science 292:107. doi: 10.1126/science. 1057987

Tatar, M., and Yin, C. M. (2001). Slow aging during insect reproductive diapause: why butterflies, grasshoppers and flies are like worms. Exp. Gerontol. 36, 723-738. doi: 10.1016/s0531-5565(00)00238-2

Toivonen, J. M., and Partridge, L. (2009). Endocrine regulation of aging and reproduction in Drosophila. Mol. Cell Endocrinol. 299, 39-50. doi: 10.1016/j. mce.2008.07.005

Tolfsen, C. C., Baker, N., Kreibich, C., and Amdam, G. V. (2011). Flight restriction prevents associative learning deficits but not changes in brain protein-adduct formation during honeybee ageing. J. Exp. Biol. 214, 1322-1332. doi: 10.1242/ jeb.049155

United Nations (2017). World Population Ageing 2017-Highlights. New York: Department of Economic and Social Affairs.

Vaiserman, A. M., Lushchak, V., and Koliada, A. K. (2018). "Epigenetics of Longevity in Social Insects," in Epigenetics of Aging and Longevity, (Netherland: Elsevier), 271-289. doi: 10.1016/b978-0-12-811060-7.00013-9

Valenzano, D. R., Aboobaker, A., Seluanov, A., and Gorbunova, V. (2017). Noncanonical aging model systems and why we need them. EMBO J. 36, 959-963. doi: $10.15252 /$ embj.201796837

Wang, T., Geng, S., Guan, Y., and Xu, W. (2018). Deacetylation of metabolic enzymes by Sirt 2 modulates pyruvate homeostasis to extend insect lifespan. Aging 10, 1053-1072. doi: 10.18632/aging.101447

Wang, X., Geng, S., Zhang, X., and Xu, W. (2020). P-S6K is associated with insect diapause via the ROS/AKT/ S6K/CREB/HIF-1 pathway in the cotton bollworm. Helicoverpa armigera. Insect Biochem. Mol. Biol. 120:103262. doi: 10.1016/j. ibmb.2019.103262

Weaver, D. B., Anzola, J. M., Evans, J. D., Reid, J. G., Reese, J. T., Childs, K. L., et al. (2007). Computational and transcriptional evidence for microRNAs in the honey bee genome. Genome Biol. 8:R97. doi: 10.1186/gb-2007-8-6-r97

Whitman, D. W., and Ananthakrishnan, T. N. (2009). Phenotypic plasticity of insects: Mechanisms and consequences. Enfield, NH: Science Publishers.

Williams, J. B., Roberts, S. P., and Elekonich, M. M. (2008). Age and natural metabolically-intensive behavior affect oxidative stress and antioxidant mechanisms. Exp. Gerontol. 43, 538-549. doi: 10.1016/j.exger.2008. 02.001

Winston, M. L. (1987). The biology of the honey bee. Cambridge, MA: Harvard University Press.
Woestmann, L., Kvist, J., and Saastamoinen, M. (2017). Fight or flight? - Flight increases immune gene expression but does not help to fight an infection. J. Evol. Biol. 30, 501-511. doi: 10.5061/dryad.38c5g

Wojciechowski, M., Lowe, R., Maleszka, J., Conn, D., Maleszka, R., and Hurd, P. J. (2018). Phenotypically distinct female castes in honey bees are defined by alternative chromatin states during larval development. Genome Res. 28, 1532-1542. doi: 10.1101/gr.236497.118

World Health Organization (2017). Global strategy and action plan on ageing and health. Switzerland: WHO.

Yan, H., Bonasio, R., Simola, D. F., Liebig, J., Berger, S. L., and Reinberg, D. (2015). DNA methylation in social insects: how epigenetics can control behavior and longevity. Annu. Rev. Entomol. 60, 435-452. doi: 10.1146/annurev-ento010814-020803

Yan, L., and Sohal, R. S. (2000). Prevention of flight activity prolongs the life span of the housefly, Musca domestica, and attenuates the age-associated oxidative damamge to specific mitochondrial proteins. Free Radic. Biol. Med. 29, 1143-1150. doi: 10.1016/s0891-5849(00)00423-8

Yang, Y. C., Boen, C., Gerken, K., Li, T., Schorpp, K., and Harris, K. M. (2016). Social relationships and physiological determinants of longevity across the human life span. Proc. Natl. Acad. Sci. U S A 113, 578-583. doi: 10.1073/pnas. 1511085112

Yocum, G. D., Rinehart, J. P., Horvath, D. P., Kemp, W. P., Bosch, J., Alroobi, R., et al. (2015). Key molecular processes of the diapause to post-diapause quiescence transition in the alfalfa leafcutting bee Megachile rotundata identified by comparative transcriptome analysis. Physiol. Entomol. 40, 103112. doi: 10.1111/phen.12093

Yuichi, E., Tsubouchi, H., and Sakamoto, K. (2016). Does DNA methylation play a role in photoperiodic diapause of moths? J. Entomol. Zool. Stud. 4, 458-460.

Zhang, X., Wang, T., Lin, X., Denlinger, D. L., and Xu, W. (2017). Reactive oxygen species extend insect life span using components of the insulin-signaling pathway. Proc. Natl. Acad. Sci. U S A 114, E7832-E7840. doi: 10.1073/pnas. 1711042114

Conflict of Interest: The authors declare that the research was conducted in the absence of any commercial or financial relationships that could be construed as a potential conflict of interest.

Copyright (c) 2020 Guo, Wang and Kang. This is an open-access article distributed under the terms of the Creative Commons Attribution License (CC BY). The use, distribution or reproduction in other forums is permitted, provided the original author(s) and the copyright owner(s) are credited and that the original publication in this journal is cited, in accordance with accepted academic practice. No use, distribution or reproduction is permitted which does not comply with these terms. 